disease and mild cognitive impairment (and in healthy controls). Biol Psychiatry 1998;43:60-68.

12. Kluger A, Gianutsos JG, Golomb J, et al. Motor/psychomotor dysfunction in normal aging, mild cognitive decline, and early Alzheimer's disease: diagnostic and differential diagnostic features. Int Psychogeriatr 1997;9:307-316.

13. American Psychiatric Association. Diagnostic and statistical manual. 3rd ed., revised. Washington, DC: American Psychiatric Association, 1987.

14. Ritchie K, Fuhrer R. A comparative study of the performance of screening tests for senile dementia using receiver operating characteristics analysis. J Clin Epidemiol 1992;45:627-637.

15. Ritchie K, Allard M, Huppert FA, et al. Computerized cognitive examination of the elderly (ECO): the development of a neuropsychological examination for clinic and population use. Int J Geriatr Psychiatry 1993;8:899-914.

16. Ritchie K, Ledésert B. The measurement of incapacity in the severely demented elderly: the validation of a behavioural assessment scale. Int J Geriatr Psychiatry 1991;6:217-226.

17. Petersen RC, Smith GE, Waring SC, et al. Aging memory and mild cognitive impairment. Int Psychogeriatr 1997;9:65-69.

18. Kendell RE. Clinical validity. Psychol Med 1989;19:45-55.

19. Rubin EH, Morris JC, Grant EA, et al. Very mild senile dementia of the Alzheimer type. I Clinical assessment. Arch Neurol 1989;46:379-382.

20. Flicker C, Ferris FH, Reisberg B. Mild cognitive impairment in the elderly: predictors of dementia. Neurology 1991;41: 1006-1009.

21. Richards M, Touchon J, Ledésert B, et al. Cognitive decline in ageing: are AAMI and AACD distinct entities? Int J Geriatr Psychiatry 1999;14:534-540.

22. Touchon J, Ritchie K. Prodromal cognitive disorder in Alzheimer's disease. Int J Geriatr Psychiatry 1999;14:556-563.

23. Hughes CP, Berg L, Danziger WL, et al. A new scale for the staging of dementia. Br J Psychiatry 1982;140:566-535.

\title{
сме Cardiovascular risk factors and cognitive decline in middle-aged adults
}

\author{
D. Knopman, MD; L.L. Boland, MPH; T. Mosley, PhD; G. Howard, DrPH; D. Liao, MD, PhD; \\ M. Szklo, MD, DrPH; P. McGovern, MD; and A.R. Folsom, MD, for the \\ Atherosclerosis Risk in Communities (ARIC) Study Investigators
}

Article abstract-Objective: To perform serial neuropsychological assessments to detect vascular risk factors for cognitive decline in the Atherosclerosis Risk in Communities cohort, a large biracial, multisite, longitudinal investigation of initially middle-aged individuals. Methods: The authors administered cognitive assessments to 10,963 individuals (8,729 white individuals and 2,234 black individuals) on two occasions separated by 6 years. Subjects ranged in age at the first assessment from 47 to 70 years. The cognitive assessments included the delayed word recall (DWR) test, a 10-word delayed free recall task in which the learning phase included sentence generation with the study words, the digit symbol subtest (DSS) of the Wechsler Adult Intelligence Scale-Revised and the first-letter word fluency (WF) test using letters F, A, and S. Results: In multivariate analyses (controlling for demographic factors), the presence of diabetes at baseline was associated with greater decline in scores on both the DSS and WF $(p<0.05)$, and the presence of hypertension at baseline was associated with greater decline on the DSS alone $(p<0.05)$. The association of diabetes with cognitive decline persisted when analysis was restricted to the 47- to 57-year-old subgroup. Smoking status, carotid intima-media wall thickness, and hyperlipidemia at baseline were not associated with change in cognitive test scores. Conclusions: Hypertension and diabetes mellitus were positively associated with cognitive decline over 6 years in this late middle-aged population. Interventions aimed at hypertension or diabetes that begin before age 60 might lessen the burden of cognitive impairment in later life.

NEUROLOGY 2001;56:42-48

Vascular risk factors are typically thought to produce deleterious effects on brain function via overt strokes. However, it is more likely that the burden of brain lesions due to cerebrovascular disease actually accumulates subclinically over years or decades. Cross-sectional data in elderly demented individuals have shown that various cardiovascular risk factors are associated with a higher risk of dementia. ${ }^{1}$ How early these risk factors may begin to exert their influence is not well understood. Several studies have noted that blood pressure during middle age is associated with later cognitive dysfunction. ${ }^{2-8}$ None of

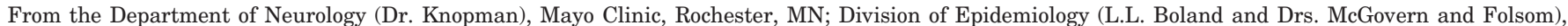

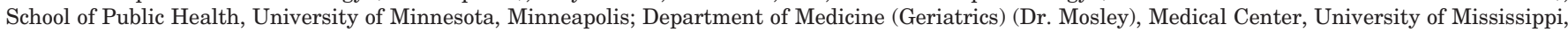

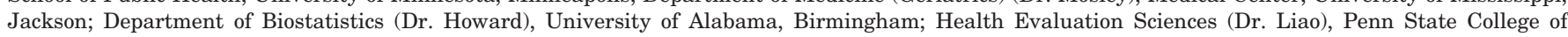
Medicine, Hershey, PA; and Department of Epidemiology (Dr. Szklo), The Johns Hopkins Medical Institutions, Baltimore, MD.

Supported by contracts N01-55015, N01-55016, N01-55018, N01-55019, N01-55020, N01-55021, N01-55022 from the National Heart, Lung and Blood Institute.

Presented at the annual meeting of the American Academy of Neurology, San Diego, CA; May 3, 2000.

Received May 18, 2000. Accepted in final form September 21, 2000.

Address correspondence and reprint requests to Dr. David Knopman, Department of Neurology, Mayo Clinic, 200 First Street SW, Rochester, MN 55905. 
these studies measured cognition in mid life, however, so the temporal relationship between hypertension and cognitive impairment has not been clear.

Studies have also shown clear relationships between diabetes mellitus, cognitive decline, and dementia (usually vascular dementia). The largest associations have been seen in studies with casecontrol designs ${ }^{9,10}$ of clinically referred patients. Population-based studies have usually,,$^{2,11,12}$ but not always,$^{13}$ shown an association of diabetes with cognitive decline in the elderly. In studies of prevalent dementia, there is a consistent link between $\mathrm{AD}^{14,15}$ and diabetes, as well as vascular dementia ${ }^{14,16,17}$ and diabetes.

The Atherosclerosis Risk in Communities (ARIC) study was initiated in 1987 as a multiethnic, multicenter investigation of vascular disease and its consequences. ${ }^{18}$ At the second visit, a cognitive battery was administered to participants. Cross-sectional results of the first (visit 2) cognitive battery have been published previously. ${ }^{19}$ At the fourth ARIC visit 6 years later, the cognitive battery was repeated. The purpose of this report is to describe the relationships between baseline cardiovascular risk factors and change in cognitive function over the 6-year interval.

Methods. The initial enrollment in ARIC has been described previously. ${ }^{18}$ Briefly, 15,792 men and women, initially aged 45 to 64 , were recruited between 1987 and 1989. The cohort was created using probability samples, employing population-wide lists (mainly drivers' licenses) or area sampling from four locales. The four sites were Forsyth County, NC; Jackson, MS; suburban Minneapolis, $\mathrm{MN}$; and Washington County, MD. Only black individuals were sampled in Jackson, MS. Approximately $13 \%$ of the Forsyth County sample was black. In the other two sites, subjects were virtually all white. The cohort underwent a comprehensive clinical examination from 1987 to 1989. The response rate was 46\% in Jackson, MS, and approximately $65 \%$ in the other three communities. Informed consent was obtained at the initial visit. The cohort has been re-examined every 3 years since the initial visit. The study was approved by the institutional review boards of each site.

At the second visit (in 1990 to 1992), conducted 3 years after the initial enrollment visit, 14,348 individuals in the ARIC cohort underwent a cognitive evaluation. For most of the current analysis, 300 of these subjects were excluded because they gave a history of stroke or TIA. This visit ("visit 2" in the overall ARIC study) constitutes the baseline visit for the current report. At visit 4, the follow-up visit for this report 6 years later, 10,963 (76\%) of the individuals in the ARIC cohort were retested.

Subjects ranged in age at the first assessment from 47 to 70 years. Among the retested individuals, there were 8,729 white subjects and 2,234 black subjects. Women $(\mathrm{n}=$ $6,126)$ were more numerous than men $(\mathrm{n}=4,837)$. Educational attainment varied widely, with $6 \%$ of subjects with $<9$ th-grade education, $45 \%$ with 9 to 12 years of education, $9 \%$ with postsecondary vocational education, and $39 \%$ with at least some college.

Cognitive testing. The cognitive assessments and the baseline performance have been presented in detail. ${ }^{19}$ The battery included the delayed word recall (DWR) test, the digit symbol subtest (DSS) of the Wechsler Adult Intelligence Scale-Revised (WAIS-R) and the first-letter word fluency (WF) test. The tests were administered by trained interviewers in a standardized order during one session in a quiet room. Interviewer performance was monitored by tape recording, and a sample of the testing sessions were reviewed to confirm that there were no systematic differences between the different interviewers who administered the tests. The same test versions were used at both visits.

The DWR ${ }^{20}$ is a test of verbal learning and recent memory that requires the participant to recall 10 common nouns following a 5-minute interval. In order to produce elaborative processing during the encoding stage of learning, individuals were required to construct sentences incorporating the words presented. During the delay interval, the digit symbol substitution test was given. After 5 minutes, free recall of the words was sought.

The DSS of the WAIS- $\mathrm{R}^{21}$ is a paper-and-pencil task requiring timed translation of numbers to symbols using a key given at the top of the test page. The test was scored as the number of correct translations completed within 90 seconds.

The WF test ${ }^{22}$ required the participant to generate as many words as possible, but not proper names or places, beginning with a particular letter of the alphabet within 60 seconds. Three separate 1-minute trial periods were used for the each of the letters F, A, and S.

Risk factor assessments. The pertinent patient status and cardiovascular risk states were defined as follows, and are described in greater detail elsewhere. ${ }^{18}$ All of these health status measures were assessed at ARIC visit 2, and interim events between visits 2 and 4 were identified.

Hypertension was considered to be present at visit 2 if systolic blood pressure (BP) was $\geq 140 \mathrm{~mm} \mathrm{Hg}$, if diastolic $\mathrm{BP}$ was $\geq 90 \mathrm{~mm} \mathrm{Hg}$, or if antihypertensive medications were being used. Systolic and diastolic BP were measured three times using a random zero sphygmomanometer in the right arm of seated participants. The mean of the last two measurements was used in all analyses.

Prevalent diabetes mellitus was defined as a fasting glucose of $\geq 126 \mathrm{mg} / \mathrm{dL}$, nonfasting glucose of $\geq 200 \mathrm{mg} / \mathrm{dL}$, a self-reported history of diabetes, or treatment for diabetes. Participants were asked to fast for 12 hours before the clinic visit. Blood was drawn from the antecubital vein of seated participants. Serum glucose was assessed by the hexokinase method.

Hyperlipidemia was defined as a low-density lipoprotein (LDL) cholesterol of $\geq 140 \mathrm{mg} / \mathrm{dL}$ or the use of cholesterol-lowering agents. Plasma lipids and lipoproteins were determined by enzymatic methods in a laboratory standardized by the Centers for Disease Control. LDL cholesterol was estimated by the Friedewald equation.

All participants were asked to bring to each ARIC clinic visit all prescription and nonprescription medications taken in the previous 2 weeks. Non-steroidal antiinflammatory drug (NSAID) use was determined by querying subjects for all prescription and nonprescription medication use at visit 2 . Although it was possible to code aspirin separately, aspirin is included among the NSAID in these analyses. We coded a subject as taking a CNSrelevant medication if they were receiving antipsychotics, 
Table 1 Changes over 6 years in cognitive tests, the Atherosclerosis Risk in Communities cohort (unadjusted data)

\begin{tabular}{lrrr}
\hline $\begin{array}{l}\text { Cognitive test/ } \\
\text { age group at visit 2 }\end{array}$ & $\mathrm{n}$ & Visit $2^{*}$ & $\begin{array}{c}\text { Visit } 4- \\
\text { visit } 2 \\
\text { change } \dagger\end{array}$ \\
\hline $\begin{array}{l}\text { Delayed Word Recall, no. of } \\
\text { words recalled }\end{array}$ & & & \\
$\quad$ All ages & 10,963 & $6.73(1.5)$ & $-0.15(0.01)$ \\
$47-57$ y & 6,060 & $6.94(1.4)$ & $-0.09(0.02)$ \\
$58-70$ y & 4,903 & $6.47(1.5)$ & $-0.23(0.23)$ \\
Digit Symbol Substitution test, & & & \\
$\quad$ no. of symbols completed & & & \\
All ages & 10,913 & $46.39(13.4)$ & $-2.60(0.07)$ \\
$47-57$ y & 6,043 & $48.62(13.5)$ & $-2.19(0.09)$ \\
$58-70$ y & 4,870 & $43.63(12.7)$ & $-3.12(0.09)$ \\
Word Fluency test, no. of & & & \\
$\quad$ words generated & & & \\
All ages & 10,937 & $34.16(12.2)$ & $-0.57(0.08)$ \\
$47-57$ y & 6,054 & $34.83(12.2)$ & $-0.37(0.10)$ \\
$58-70$ y & 4,883 & $33.34(12.1)$ & $-0.81(0.11)$ \\
\hline
\end{tabular}

* Values are mean (SD).

$\uparrow$ Values are mean (SE).

antidepressants, anxiolytics, narcotic analgesics, anticonvulsants, or antineoplastic agents.

Carotid wall intima-media thickness (IMT) was determined by high resolution B-mode ultrasound, as previously described. ${ }^{23}$ IMT was measured at three sites bilaterally, and an overall average of the mean IMT of the six arterial segments was calculated. The mean IMT used in analysis was further adjusted for reader differences and time trends. For the purposes of the analyses, carotid IMT was divided into tertiles: $<0.65 \mathrm{~mm}, 0.65$ to $0.76 \mathrm{~mm}$, and $>0.76 \mathrm{~mm}$.

Prevalent stroke was defined as those strokes that were self-reported by subjects at the second ARIC visit.

Incident stroke was defined as a stroke meeting ARIC criteria, as verified by an ARIC clinician through review of medical records..$^{24,25}$ To date, the identification and validation of incident strokes is complete only from baseline through December 31, 1996. Because the testing cycle for the follow-up cognitive assessments occurred over the 3-year period of January 1996 to January 1999, some incident strokes have not been enumerated. Because adjustment for incident stroke would be only partial, subjects with incident stroke were excluded from multivariate analyses. We chose to include in this report data on subjects with incident stroke for descriptive purposes and because their data illuminates other aspects of the analysis.

Statistical methods. Change scores for cognitive tests were calculated as visit 4 minus visit 2 values for each individual. Mean change scores were tabulated by age level. Change scores were computed for strata of each putative vascular risk factor ${ }^{19}$ using linear regression to control for age, gender, race-center, educational level, site, and CNS-relevant medications. We performed the analyses both with and without adjusting for the visit 2 performance. Because the adjustment for the visit 2 scores had virtually no effect on the outcomes, we report only the analyses without the adjustment. Additional analyses computed change scores for strata of each putative risk factor broken down by race, but still controlling for age, gender, center, educational level, site, and CNS-relevant medications. Medication use was determined from visit 2 only. Age was treated as a continuous variable in risk-factor analyses. The SAS statistical package (SAS Institute, Cary, NC) was used for these analyses.

Results. The mean duration of follow-up was 6.0 (SD 0.3 ) years with a range of 3.6 to 8.8 years. Mean change scores over the follow-up interval for the DWR, DSS, and WF tests are given in table 1. Each mean score declined, but declines were relatively small-equivalent to $0.1 \mathrm{SD}$ for DWR, 0.2 SD for DSS, and 0.05 SD for WF. Scores declined more in older than younger participants.

Table 2 Adjusted mean change in cognitive function tests by level of cardiovascular risk factors in the Atherosclerosis Risk in Communities cohort

\begin{tabular}{|c|c|c|c|c|}
\hline CVD risk factor & $\mathrm{n}$ & DWR & DSS & WF \\
\hline \multicolumn{5}{|l|}{ Hyperlipidemia* } \\
\hline No & 6,077 & -0.14 & -2.49 & -0.55 \\
\hline Yes & 4,533 & -0.14 & -2.60 & -0.47 \\
\hline \multicolumn{5}{|l|}{ Smoking } \\
\hline Never & 4,547 & -0.12 & -2.52 & -0.59 \\
\hline Former & 4,171 & -0.16 & -2.55 & -0.43 \\
\hline Current & 2,076 & -0.15 & -2.62 & -0.58 \\
\hline \multicolumn{5}{|l|}{ Diabetes } \\
\hline No & 9,428 & -0.13 & -2.44 & -0.43 \\
\hline Yes & 1,329 & -0.21 & $-3.35 \dagger$ & $-1.14 \dagger$ \\
\hline \multicolumn{5}{|c|}{ Carotid IMT thickness $\ddagger$} \\
\hline \multicolumn{5}{|l|}{ Tertile } \\
\hline I & 3,685 & -0.15 & -2.49 & -0.40 \\
\hline II & 3,456 & -0.15 & -2.50 & -0.59 \\
\hline III & 3,278 & -0.12 & -2.75 & -0.57 \\
\hline \multicolumn{5}{|l|}{ Hypertension§ } \\
\hline No & 7,301 & -0.14 & -2.43 & -0.46 \\
\hline Yes & 3,466 & -0.15 & $-2.82 \S$ & -0.68 \\
\hline \multicolumn{5}{|c|}{$\begin{array}{l}\text { Nonsteroidal anti- } \\
\text { inflammatory drug } \\
\text { use }\end{array}$} \\
\hline No & 8,508 & -0.15 & -2.51 & -0.48 \\
\hline Yes & 2,291 & -0.12 & -2.71 & -0.69 \\
\hline
\end{tabular}

Subjects with incident stroke were excluded. The analyses were adjusted for age, gender, race-center, education level, and use of CNS medications at visit 2 .

* Low-density lipoprotein cholesterol $\geq 140 \mathrm{mg} / \mathrm{dL}$ or use of cholesterol-lowering medication.

$\dagger p<0.05$.

$\ddagger$ Carotid intimal-media thickness (IMT): tertile $\mathrm{I}=<0.65 \mathrm{~mm}$; tertile II $=0.65-0.76 \mathrm{~mm}$; tertile III $=>0.76 \mathrm{~mm}$.

$\S$ Systolic blood pressure $\geq 140$ or diastolic blood pressure $\geq 90$ $\mathrm{mm} \mathrm{Hg}$ or use of antihypertensive medication.

CVD $=$ cardiovascular disease DWR $=$ Delayed Word Recall test; DSS $=$ Digit Symbol Substitution test; WF $=$ Word Fluency test. 
Table 3 Adjusted mean change in cognitive function by level of cardiovascular risk factors, stratified by age at visit 2 in the Atherosclerosis Risk in Communities cohort

\begin{tabular}{lrrrr}
\hline CVD risk factor & $\mathrm{n}$ & DWR & DSS & WF \\
\hline $\begin{array}{l}\text { Age }<58 \text { y } \\
\text { Diabetes }\end{array}$ & & & & \\
$\quad$ No & 5,339 & -0.08 & -2.07 & -0.24 \\
$\quad$ Yes & 629 & -0.12 & $-2.82^{*}$ & $-0.98^{*}$ \\
Hypertension $\dagger$ & & & & \\
$\quad$ No & 4,359 & -0.08 & -2.15 & -0.30 \\
$\quad$ Yes & 1,624 & -0.10 & -2.15 & -0.45 \\
Age $\geq 58$ y & & & & \\
Diabetes & & & & \\
$\quad$ No & 4,089 & -0.20 & -2.90 & -0.67 \\
$\quad$ Yes & 700 & -0.32 & $-3.94^{*}$ & $-1.35^{*}$ \\
Hypertension $\dagger$ & & & & \\
$\quad$ No & 2,942 & -0.22 & -2.75 & -0.66 \\
$\quad$ Yes & 1,842 & -0.21 & $-3.54^{*}$ & -0.94 \\
\hline
\end{tabular}

Subjects with incident stroke were excluded. The analyses were adjusted for age, gender, race-center, education level, and use of CNS medications at visit 2 .

$* p<0.05$.

$\uparrow$ Systolic blood pressure $\geq 140$ or diastolic blood pressure $\geq 90$ $\mathrm{mm} \mathrm{Hg}$ or use of antihypertensive medication.

CVD $=$ cardiovascular disease DWR $=$ Delayed Word Recall test; DSS $=$ Digit Symbol Substitution test; WF $=$ Word Fluency test.

Baseline diabetes and hypertension were associated with greater declines in scores on either DSS or WF (table 2). Participants with diabetes had a greater decline by 0.9 symbols on the DSS and 0.7 words on WF than nondiabetic subjects. Compared to nonhypertensive subjects, hypertensive subjects had a 0.4 greater symbol decline on the DSS. The following baseline risk factors were not associated with declines on any of the cognitive tests: carotid wall IMT, smoking, NSAID use, and hyperlipidemia.

There were 83 incident strokes in the cohort. Mean scores declined four to ninefold more in subjects with incident stroke in the follow-up interval compared with subjects with no incident stroke ( $p<0.05$, data not shown). On average, participants who had incident stroke declined 0.9 more words on the DWR, 6.7 more symbols on the DSS, and 4.3 more words on the WF versus participants who did not have incident stroke. History of stroke at baseline (visit 2) was not associated with cognitive decline over the follow-up period (data not shown).

We also performed analyses using the systolic blood pressure cut points used by Glynn et al., ${ }^{5}$ and did not find a U-shaped association with cognitive function on any of the three tests in our cohort. In fact, for the DSS and WF, the group with the lowest systolic $\mathrm{BP}(<130 \mathrm{~mm} \mathrm{Hg})$ had the least cognitive decline.

Interaction terms between age and diabetes and hypertension in the basic multivariate analyses showed that the hypertension association with DSS test change score differed by age $(p<0.05)$. In order to better define the rela- tionship between cognitive decline and age, we stratified the cohort into those $<58$ years of age and those $\geq 58$ years of age (table 3). Diabetes mellitus was a risk factor for cognitive decline even in the younger age group on both DSS and WF. Hypertension proved to be a risk factor only in older participants.

In analyses broken down by age ( $<58$ or $\geq 58$ years) and race, the associations between diabetes and DSS and WF change scores were significant $(p<0.05)$ in the older black subjects, as well as in both the younger and older white subgroups, and similar in magnitude to the values shown in table 3 for the entire group. In the younger black subgroup, the diabetes-cognitive change score associations were in the same directions and nearly the same magnitude as observed for the entire cohort, but did not reach significance. For hypertension and cognitive test scores, there were no significant associations among black participants, regardless of age. However, in the older black subjects, the association between hypertension and change scores on the DSS was of the same magnitude as shown in table 3 for the entire cohort. The association between change in scores on the DSS and hypertension was significant $(p<0.05)$ in the older white subjects. Among older

Table 4 Comparison of visit 2 characteristics of participants in the Atherosclerosis Risk in Communities Study who returned for visit 4 and those who did not return

\begin{tabular}{|c|c|c|c|}
\hline Characteristic & $\begin{array}{c}\text { Cognitive } \\
\text { change data } \\
\text { available } \\
(\mathrm{n}=10,882)\end{array}$ & $\begin{array}{c}\text { Cognitive } \\
\text { change data } \\
\text { not available } \\
(\mathrm{n}=3,166)\end{array}$ & $p$ Value* \\
\hline Male sex, $\%$ & 44.0 & 45.9 & 0.055 \\
\hline Black, \% & 20.2 & 39.7 & $<0.001$ \\
\hline Age, $\mathrm{y}$, mean $\pm \mathrm{SD}$ & $56.8 \pm 5.7$ & $57.6 \pm 5.8$ & $<0.0001$ \\
\hline $\mathrm{BMI}, \mathrm{kg} / \mathrm{m}^{2}$, mean $\pm \mathrm{SD}$ & $27.9 \pm 5.2$ & $28.4 \pm 6.0$ & $<0.0001$ \\
\hline \multicolumn{4}{|l|}{ Smoking, \% } \\
\hline Current & 19.3 & 32.4 & \\
\hline Former & 38.6 & 35.2 & $<0.001$ \\
\hline Never & 42.1 & 32.5 & \\
\hline \multicolumn{4}{|l|}{ Education, \% } \\
\hline$<9$ th grade & 6.2 & 16.5 & \\
\hline 9-12 grade & 45.4 & 48.1 & $<0.001$ \\
\hline Vocational school & 8.9 & 7.4 & \\
\hline College + & 39.5 & 28.0 & \\
\hline Diabetes, $\%$ & 12.4 & 22.8 & $<0.001$ \\
\hline Hypertensive, \% & 32.4 & 45.9 & $<0.001$ \\
\hline Incident stroke, $\%$ & 0.8 & 0.4 & 0.055 \\
\hline $\begin{array}{l}\text { Visit } 2 \mathrm{DWR} \text { score, } \\
\text { mean } \pm \mathrm{SD}\end{array}$ & $6.7 \pm 1.5$ & $6.2 \pm 1.7$ & $<0.0001$ \\
\hline $\begin{array}{l}\text { Visit } 2 \text { DSS score, mean } \\
\quad \pm \mathrm{SD}\end{array}$ & $46.4 \pm 13.3$ & $38.8 \pm 15.4$ & $<0.0001$ \\
\hline $\begin{array}{l}\text { Visit } 2 \text { WF score, mean } \\
\quad \pm \mathrm{SD}\end{array}$ & $34.2 \pm 12.2$ & $29.8 \pm 13.0$ & $<0.0001$ \\
\hline
\end{tabular}

$* p$ Value for test of significant difference in means ( $t$-test) or proportions $\left(\chi^{2}\right)$.

BMI $=$ body mass index; DWR $=$ Delayed Word Recall; DSS = Digit Span Substitution; WF = Word Fluency. 
black subjects, current smokers (compared to former smokers but not never smokers) and those in tertile III of carotid intimal thickness (compared to tertile II but not tertile I) had greater decline on the DSS. There were no other race-specific associations with other risk factors.

We compared subjects who returned to visit 4 to those who did not (table 4). There were substantial differences demographically and, in terms of risk factors and baseline cognitive status, the latter was worse in those who did not return.

Discussion. We have documented that decline in cognitive function in a middle-aged and youngelderly cohort was greater in participants with hypertension, diabetes mellitus, or incident stroke. The performance decrements associated with hypertension and diabetes that we observed were small and probably not clinically significant to the participants. However, from a pathogenetic perspective, our observations offer evidence for the initiation of cognitive impairment associated with diabetes and hypertension. We believe that our cohort is the youngest to date in which neuropsychological decline associated with cardiovascular risk factors has been documented using a longitudinal design. A very recent study that enrolled 59- to 71-year-old subjects also found an association between hypertension and cognitive decline over a 4 -year observation period. ${ }^{8}$ Similar associations between cardiovascular risk factors and cognitive decline have been observed in older populations, particularly in the Cardiovascular Health Study, ${ }^{2}$ the Honolulu Heart Study, ${ }^{4,16}$ the Rotterdam Study, ${ }^{26}$ the Framingham Heart Study, ${ }^{11}$ and the Goteborg Longitudinal Study. ${ }^{27}$

In the baseline assessment of the individuals in the ARIC cohort, cardiovascular risk factors were also associated with lower cognition. ${ }^{19,28}$ Longitudinal studies such as the current one provide stronger evidence than cross-sectional studies for the existence of linkage between cardiovascular risk factors and cognitive decline.

Of our three cognitive tests, change on the DSS was most strongly associated with risk factors. Because it is a timed test, it may be more sensitive to subcortical vascular lesions in the striatum and in cortico-cortical and cortico-subcortical pathways. The association of hypertension and diabetes mellitus with the decline on the DSS is notably similar to that observed in the Cardiovascular Health Study. ${ }^{2}$ Our data extend the observations in the Cardiovascular Health Study of older patients to a younger age group. The association between diabetes mellitus and change on the WF task in our study also expands upon the generality of the relationship between diabetes and cognition by showing the association between diabetes and another mental agility task.

Almost all studies that have examined the association of hypertension with declining cognition have found a positive association between the two. The negative study by Prince et al. ${ }^{7,29}$ may be explained by the absence of nonhypertensive subjects in the study sample. Several studies with older subjects ${ }^{5,30}$ found a U-shaped association of blood pressure with subsequent cognitive change scores in populationbased cohorts. We failed to find a negative association of low blood pressure and cognition. Two studies $^{5,30}$ used different cognitive screening tools (neither study used timed tests) than we did. In the older age range of the other two studies, ${ }^{5,30}$ lower blood pressure might be more likely to be due to a pathologic process, whereas in our young patients, low blood pressure may be part of the normal range of variation.

Three studies in older subjects ${ }^{3,4,6}$ have found that mid-life hypertension was associated with diminished cognitive performance in later life. Our study measured blood pressure at nearly as young an age as that performed in the Honolulu Heart Study ${ }^{4}$ or the Framingham Heart Study, ${ }^{3}$ but not as young as a study of twins by Carmelli et al. ${ }^{6}$ Our study design enabled us to detect an association with cognitive decline at a younger age than these three other studies.

Studies of diabetes mellitus and cognition have shown some inconsistency. Case-control studies ${ }^{9,10}$ from clinical samples have shown cognitive impairment in diabetic subjects compared to controls. Some groups found no associations either with crosssectionally measured cognition ${ }^{13}$ or with a diagnosis of dementia, ${ }^{16}$ whereas other population studies reported diabetes to be an independent risk factor for either cognitive impairment ${ }^{11,12}$ or dementia. ${ }^{14,15,17}$ Only two other studies have measured cognitive function longitudinally in diabetics. One showed an association similar to ours, ${ }^{2}$ while the other, based on volunteers in the Baltimore Longitudinal Study, ${ }^{31}$ showed no evidence for greater cognitive decline in diabetics.

The effect of incident stroke on cognitive decline was substantial and reflected in the cognitive tests. The number of incident strokes in our cohort was small and not complete, however. Several other longitudinal studies have shown that incident stroke is a risk factor for cognitive decline and dementia. ${ }^{32-37}$ Clinicopathologic studies have shown that patients with $\mathrm{AD}$ and infarcts are more demented than patients with only Alzheimer pathology. ${ }^{38,39}$

The lack of an association of carotid artery IMT with change in cognition is notable because carotid artery IMT was correlated with baseline DSS performance in the ARIC cohort $^{19}$ and is a risk factor for stroke. ${ }^{40,41}$ A longitudinal study such as this one helps to identify conditions-cognitive impairment and carotid artery disease - that may have common mediators, but may not be causally related themselves.

Our memory test, the DWR, showed negligible changes over 6 years in the study population as a whole. It was surprising to us that change in the DWR was not associated with diabetes or hypertension. Glynn et al. ${ }^{5}$ also failed to show a consistent 
association of hypertension with longitudinal cognitive change on their six-item memory test. Perhaps the DWR and the memory test used by Glynn et al. ${ }^{5}$ lack sufficient sensitivity. Conversely, ARIC subjects who had strokes in the interval between visits 2 and 4 experienced decline on the DWR in addition to the other two tests. Perhaps the effects of diabetes and hypertension are somewhat distinct from that of infarction, per se, in terms of the anatomic locus of the brain injury.

Among ARIC participants, race had a relatively minor impact on associations between risk factors and cognition. Because sample sizes were lower in race-specific analyses, we were not able to detect associations of small magnitude, but the associations with diabetes and hypertension that were seen in the combined cohort were quite similar across racial groups.

The mechanism by which hypertension and diabetes mellitus cause impaired cognition was not addressed in the current study, but one candidate other than overt cerebral infarction might be demyelination or microinfarction in the cerebral white matter. In both the ARIC study ${ }^{42}$ and Cardiovascular Health Study cross-sectional data, ${ }^{43}$ white matter lesions by MRI and hypertension were correlated. Furthermore, white matter changes have been correlated with poorer cognitive performance in twin studies ${ }^{44}$ and population-based studies. ${ }^{37,45} \mathrm{~A}$ report of the relationships between brain MRI findings and cognition assessed at visit 3 in ARIC is currently being prepared. Silent cerebral infarctions are another mechanism by which hypertension produces brain injury. In a subset of the ARIC cohort, hypertension was associated with an increased risk for silent cerebral infarcts. ${ }^{46}$ The associations of risk factors, brain lesions, and cognition is complex, however. In one study ${ }^{46}$ cigarette smoking had the most powerful association with silent cerebral infarcts; in the current study, cigarette smoking had no associations with cognitive change.

Strengths of this study include its populationbased, ethnically diverse cohort, its very large sample size, and its longitudinal nature. The limitations of this study are few. Longitudinal studies have much attrition, and as we have shown (table 4), ARIC participants who dropped out or died were more impaired than those who returned for followup. The attrition of more impaired individuals may have lessened our ability to show associations between cognitive decline and risk factors. Our cognitive battery was limited. It is possible that other measures of abstract reasoning, executive function, visuospatial function, or language could have revealed a different pattern of associations with cardiovascular risk factors. In addition, our analyses involved testing of associations of multiple risk factors, raising the possibility of type I errors.

Our longitudinal observations show that diabetes and hypertension were associated with erosion of cognitive function, as early as late middle age. We hypothesize that the interaction of vascular risk factor-induced cognitive decline and the rising probability of Alzheimer pathology in the 7th and 8th decades of life increases the probability of dementia. Interventions aimed at hypertension or diabetes that begin before age 60 years might lessen the burden of cognitive impairment in later life. Although not all studies that have examined the effects of treatment of hypertension on dementia have been positive, ${ }^{47}$ some encouraging findings have been reported. ${ }^{48}$

\section{Acknowledgment}

The authors thank the staff and participants in the ARIC study for their important contributions.

\section{References}

1. Hofman A, Ott A, Breteler MM, et al. Atherosclerosis, apolipoprotein E, and prevalence of dementia and Alzheimer's disease in the Rotterdam Study. Lancet 1997;349:151-154.

2. Haan MN, Shemanski L, Jagust WJ, Manolio TA, Kuller L. The role of APOE epsilon4 in modulating effects of other risk factors for cognitive decline in elderly persons. JAMA 1999; 282:40-46.

3. Elias MF, Wolf PA, D'Agostino RB, Cobb J, White LR. Untreated blood pressure level is inversely related to cognitive functioning: the Framingham Study. Am J Epidemiol 1993; 138:353-364.

4. Launer LJ, Masaki K, Petrovitch H, Foley D, Havlik RJ. The association between midlife blood pressure levels and late-life cognitive function. The Honolulu-Asia Aging Study. JAMA 1995;274:1846-1851.

5. Glynn RJ, Beckett LA, Hebert LE, Morris MC, Scherr PA, Evans DA. Current and remote blood pressure and cognitive decline. JAMA 1999;281:438-445.

6. Carmelli D, Swan GE, Reed T, et al. Midlife cardiovascular risk factors, ApoE, and cognitive decline in elderly male twins. Neurology 1998;50:1580-1585.

7. Prince M, Cullen M, Mann A. Risk factors for Alzheimer's disease and dementia: a case-control study based on the MRC elderly hypertension trial. Neurology 1994;44:97-104.

8. Tzourio C, Dufouil C, Ducimetiere P, Alperovitch A. Cognitive decline in individuals with high blood pressure: a longitudinal study in the elderly. EVA Study Group Epidemiology of Vascular Aging. Neurology 1999;53:1948-1952.

9. Perlmuter LC, Hakami MK, Hodgson-Harrington C, et al. Decreased cognitive function in aging non-insulin-dependent diabetic patients. Am J Med 1984;77:1043-1048.

10. Worrall G, Moulton N, Briffett E. Effect of type II diabetes mellitus on cognitive function. J Fam Pract 1993;36:639-643.

11. Elias PK, Elias MF, D'Agostino RB, et al. NIDDM and blood pressure as risk factors for poor cognitive performance. The Framingham Study Diabetes Care 1997;20:1388-1395.

12. Kalmijn S, Feskens EJ, Launer LJ, Stijnen T, Kromhout D. Glucose intolerance, hyperinsulinaemia and cognitive function in a general population of elderly men. Diabetologia 1995;38: 1096-1102.

13. Scott RD, Kritz-Silverstein D, Barrett-Connor E, Wiederholt WC. The association of non-insulin-dependent diabetes mellitus and cognitive function in an older cohort. J Am Geriatr Soc 1998;46:1217-1222.

14. Ott A, Stolk RP, Hofman A, van Harskamp F, Grobbee DE, Breteler MM. Association of diabetes mellitus and dementia: the Rotterdam Study. Diabetologia 1996;39:1392-1397.

15. Ott A, Stolk RP, van Harskamp F, Pols HA, Hofman A, Breteler MM. Diabetes mellitus and the risk of dementia: the Rotterdam Study. Neurology 1999;53:1937-1942.

16. Curb JD, Rodriguez BL, Abbott RD, et al. Longitudinal association of vascular and Alzheimer's dementias, diabetes, and glucose tolerance. Neurology 1999;52:971-975.

17. Leibson CL, Rocca WA, Hanson VA, et al. Risk of dementia among persons with diabetes mellitus: a population-based cohort study. Am J Epidemiol 1997;145:301-308. 
18. ARIC Investigators. The Atherosclerosis Risk in Communities (ARIC) Study: design and objectives. Am J Epidemiol 1989; 129:687-702.

19. Cerhan JR, Folsom AR, Mortimer JA, et al. Correlates of cognitive function in middle-aged adults. Atherosclerosis Risk in Communities (ARIC) Study Investigators. Gerontology 1998;44:95-105.

20. Knopman DS, Ryberg S. A verbal memory test with high predictive accuracy for dementia of the Alzheimer type. Arch Neurol 1989;46:141-145.

21. Wechsler D. The Wechsler Adult Intelligence Scale-Revised. New York, NY: The Psychological Corporation, 1981.

22. Lezak MD. Neuropsychological assessment, 3rd ed., New York, NY: Oxford University Press, 1995.

23. Riley WA, Barnes RW, Applegate WB, et al. Reproducibility of noninvasive ultrasonic measurement of carotid atherosclerosis. The Asymptomatic Carotid Artery Plaque Study. Stroke 1992;23:1062-1068.

24. Toole JF, Lefkowitz DS, Chambless LE, Wijnberg L, Paton CC, Heiss G. Self-reported transient ischemic attack and stroke symptoms: methods and baseline prevalence. The ARIC Study 1987-1989. Am J Epidemiol 1996:144:849-856.

25. Rosamond WD, Folsom AR, Chambless LE, et al. Stroke incidence and survival among middle-aged adults: 9-year follow-up of the Atherosclerosis Risk in Communities (ARIC) cohort. Stroke 1999;30:736-743.

26. Breteler MM, Bots ML, Ott A, Hofman A. Risk factors for vascular disease and dementia. Haemostasis 1998;28:167173

27. Skoog I, Lernfelt B, Landahl S, et al. 15-year longitudinal study of blood pressure and dementia. Lancet 1996;347:11411145.

28. Liao D, Mo J, Lamar V, et al. Cognitive function and hypertension, its treatment and control-the ARIC study. Circulation 1999;100:I231.

29. Prince M, Lewis G, Bird A, Blizard R, Mann A. A longitudinal study of factors predicting change in cognitive test scores over time, in an older hypertensive population. Psychol Med 1996; 26:555-568.

30. Guo Z, Viitanen M, Fratiglioni L, Winblad B. Low blood pressure and dementia in elderly people: the Kungsholmen project. BMJ 1996;312:805-808.

31. Robertson-Tchabo EA, Arenberg D, Tobin JD, Plotz JB. A longitudinal study of cognitive performance in noninsulin dependent (type II) diabetic men. Exp Gerontol 1986;21:459467.

32. Kokmen E, Whisnant JP, O'Fallon WM, Chu CP, Beard CM. Dementia after ischemic stroke: a population-based study in Rochester, Minnesota (1960-1984). Neurology 1996;46:154159

33. Tatemichi TK, Foulkes MA, Mohr JP, et al. Dementia in stroke survivors in the Stroke Data Bank cohort. Prevalence, incidence, risk factors, and computed tomographic findings. Stroke 1990;21:858-866.

34. Tatemichi TK, Desmond DW, Mayeux R, et al. Dementia after stroke: baseline frequency, risks, and clinical features in a hospitalized cohort. Neurology 1992;42:1185-1193.
35. Tatemichi TK, Paik M, Bagiella E, et al. Risk of dementia after stroke in a hospitalized cohort: results of a longitudinal study. Neurology 1994;44:1885-1891.

36. Longstreth WT Jr, Bernick C, Manolio TA, Bryan N, Jungreis CA, Price TR. Lacunar infarcts defined by magnetic resonance imaging of 3660 elderly people: the Cardiovascular Health Study. Arch Neurol 1998;55:1217-1225.

37. Kuller LH, Shemanski L, Manolio T, et al. Relationship between ApoE, MRI findings, and cognitive function in the Cardiovascular Health Study. Stroke 1998;29:388-398.

38. Snowdon DA, Greiner LH, Mortimer JA, Riley KP, Greiner PA, Markesbery WR. Brain infarction and the clinical expression of Alzheimer disease. The Nun Study. JAMA 1997;277: 813-817.

39. Heyman A, Fillenbaum GG, Welsh-Bohmer KA, et al. Cerebral infarcts in patients with autopsy-proven Alzheimer's disease: CERAD, part XVIII. Consortium to Establish a Registry for Alzheimer's Disease. Neurology 1998;51:159-162.

40. O'Leary DH, Polak JF, Kronmal RA, Manolio TA, Burke GL, Wolfson SK Jr. Carotid-artery intima and media thickness as a risk factor for myocardial infarction and stroke in older adults. Cardiovascular Health Study Collaborative Research Group. N Engl J Med 1999;340:14-22.

41. Chambless LE, Shahar E, Sharrett AR, et al. Association of transient ischemic attack/stroke symptoms assessed by standardized questionnaire and algorithm with cerebrovascular risk factors and carotid artery wall thickness. The ARIC Study 1987-1989. Am J Epidemiol 1996:144:857-866.

42. Liao D, Cooper L, Cai J, et al. The prevalence and severity of white matter lesions, their relationship with age, ethnicity, gender, and cardiovascular disease risk factors: the ARIC Study. Neuroepidemiology 1997;16:149-162.

43. Longstreth WT Jr, Manolio TA, Arnold A, et al. Clinical correlates of white matter findings on cranial magnetic resonance imaging of 3301 elderly people. The Cardiovascular Health Study. Stroke 1996;27:1274-1282.

44. Swan GE, DeCarli C, Miller BL, et al. Association of midlife blood pressure to late-life cognitive decline and brain morphology. Neurology 1998;51:986-993.

45. Breteler MM, van Swieten JC, Bots ML, et al. Cerebral white matter lesions, vascular risk factors, and cognitive function in a population-based study: the Rotterdam Study. Neurology 1994;44:1246-1252.

46. Howard G, Wagenknecht LE, Cai J, Cooper L, Kraut MA, Toole JF. Cigarette smoking and other risk factors for silent cerebral infarction in the general population. Stroke 1998;29: 913-917.

47. Prince MJ, Bird AS, Blizard RA, Mann AH. Is the cognitive function of older patients affected by antihypertensive treatment? Results from 54 months of the Medical Research Council's trial of hypertension in older adults. BMJ 1996;312:801805.

48. Forette F, Seux ML, Staessen JA, et al. Prevention of dementia in randomised double-blind placebo-controlled Systolic Hypertension in Europe (Syst-Eur) trial. Lancet 1998;352:13471351 


\section{Neurology}

\section{Cardiovascular risk factors and cognitive decline in middle-aged adults \\ D. Knopman, L.L. Boland, T. Mosley, et al.}

Neurology 2001;56;42-48

DOI 10.1212/WNL.56.1.42

\section{This information is current as of January 9, 2001}

\section{Updated Information \& Services}

References

Citations

Subspecialty Collections

Permissions \& Licensing

Reprints including high resolution figures, can be found at: http://n.neurology.org/content/56/1/42.full

This article cites 45 articles, 19 of which you can access for free at: http://n.neurology.org/content/56/1/42.full\#ref-list-1

This article has been cited by 57 HighWire-hosted articles: http://n.neurology.org/content/56/1/42.full\#\#otherarticles

This article, along with others on similar topics, appears in the following collection(s):

Alzheimer's disease

http://n.neurology.org/cgi/collection/alzheimers_disease

MCI (mild cognitive impairment)

http://n.neurology.org/cgi/collection/mci_mild_cognitive_impairment Vascular dementia

http://n.neurology.org/cgi/collection/vascular_dementia

Information about reproducing this article in parts (figures,tables) or in its entirety can be found online at:

http://www.neurology.org/about/about_the_journal\#permissions

Information about ordering reprints can be found online: http://n.neurology.org/subscribers/advertise

Neurology ${ }^{\circledR}$ is the official journal of the American Academy of Neurology. Published continuously since 1951, it is now a weekly with 48 issues per year. Copyright . All rights reserved. Print ISSN: 0028-3878. Online ISSN: 1526-632X.

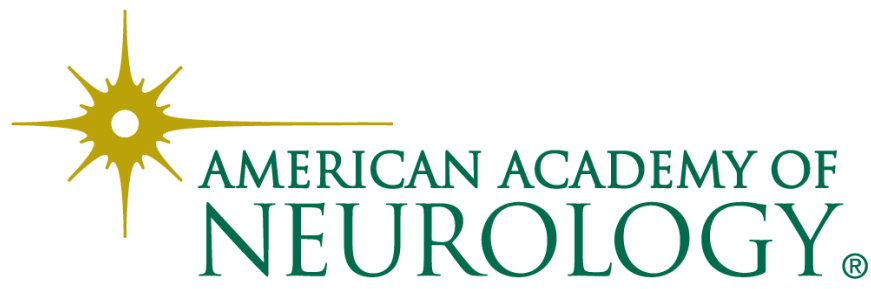

